\title{
Atributos físicos e conservacionistas da bacia hidrográfica do Rio Santa Helena
}

\author{
Wesley Vicente CLAUDINO ${ }^{1 *}$, Vinícius Alves Andrade OLIVEIRA ${ }^{1}$, Edgley Pereira SILVA ${ }^{1}$, \\ Sylvia Karla Ferreira SANTOS ${ }^{1}$, Ademilson Sampaio OLIVEIRA ${ }^{1}$ \\ ${ }^{1}$ Faculdade de Ciências Biológicas e Agrárias, Universidade do Estado de Mato Grosso, Alta Floresta, MT, Brasil. \\ (ORCID; *; 0000-0003-3006-3136; 0000-0002-9502-3437; 0000-0002-0424-9685; 0000-0003-0816-9559) \\ *E-mail: wesleyherbam@gmail.com (ORCID: 0000-0002-4074-1706)
}

\begin{abstract}
Recebido em: 12/07/2018; Aceito em: 28/10/2019; Publicado em: 04/02/2020.
RESUMO: O objetivo do trabalho foi verificar as características físicas e conservacionistas da bacia hidrográfica do Rio Santa Helena com o uso do sensoriamento remoto e geoprocessamento, e criar um modelo empírico de vulnerabilidade a erosão para a região. Foram realizadas as análises da densidade de drenagens, área total, perímetro total, coeficiente de compacidade, fator de forma, índice de circularidade, padrão de drenagem, comprimento do curso d'água principal, comprimento total dos cursos d'água e ordem dos cursos d'água. Para a criação do modelo de vulnerabilidade à erosão foi realizada a classificação supervisionada através do algoritmo de máxima verossimilhança, o cálculo do potencial erosivo das chuvas para a região, além da análise da declividade e do tipo de solo. Os resultados obtidos foram: área de drenagem 1461,68 $\mathrm{km}^{2}$; perímetro 329,16 $\mathrm{km}$; comprimento axial $68,81 \mathrm{~km}$; coeficiente de compacidade 2,41; fator de forma 0,31 e o índice de circularidade 0,17 . A hidrografia apresenta padrão dendrítico, de $5^{a}$ ordem e com densidade de drenagem baixa $\left(0,96 \mathrm{~km} / \mathrm{km}^{2}\right)$. Esses dados indicam um formato irregular e alongado da bacia. Quanto ao potencial erosivo, a bacia apresenta de baixo a médio risco, principalmente devido à declividade e à cobertura do solo.
\end{abstract}

Palavras-chave: manejo de bacias hidrográficas; geoprocessamento; modelagem erosiva.

\section{Physical and conservational atributes of the Santa Helena River water basin}

\begin{abstract}
The objective of this work was to verify the physical and conservation characteristics of the Santa Helena River basin using remote sensing and geoprocessing, and to create an empirical model of erosion vulnerability for the region. Drainage density, total area, total perimeter, compactness coefficient, shape factor, circularity index, drainage pattern, length of main watercourse, total length of watercourses and order of watercourses were analyzed. For the creation of the erosion vulnerability model, the supervised classification was performed through the maximum likelihood algorithm, the rainfall erosive potential calculation for the region, as well as the slope and soil type analysis. The results obtained were: drainage area $1461.68 \mathrm{~km}^{2}$; perimeter $329.16 \mathrm{~km}$; axial length $68.81 \mathrm{~km}$; compactness coefficient 2.41; form factor 0.31 and circularity index 0.17 . The hydrography has a dendritic pattern of 5 th order and low drainage density $\left(0.96 \mathrm{~km} / \mathrm{km}^{2}\right)$. These data indicate an irregular and elongated shape of the basin. As for the erosive potential, the basin presents low to medium risk, mainly due to the slope and the ground cover.
\end{abstract}

Keywords: management of watersheds; geoprocessing; erosive modeling.

\section{INTRODUÇÃO}

O processo de ocupação e uso da terra na região da Amazônia, aconteceu de uma forma desorganizada, sem devido cuidado em relação aos padrões de ocupação (FEARNSIDE, 2006), sobretudo a nível de bacias hidrográficas. Essa ocupação desordenada pode ter um efeito negativo nessas áreas, e dentre os principais impactos causados por essas mudanças de uso da terra está a substituição da vegetação nativa por pastagens que pode influenciar no ciclo hidrológico a nível de microbacia.

Segundo Tundisi; Tundisi (2010), as atividades agropecuárias alteram os processos biogeoquímicos dos sistemas naturais, principalmente gerando impactos nos recursos hídricos. Portanto, a gestão dos recursos naturais deve ser realizada com base nessas áreas de captação, isso se torna importante para a região amazônica, sobretudo na região norte que sofre uma intensa mudança no uso da terra. Segundo Spletozer et al. (2014), no município de Alta
Floresta, localizado ao norte no Mato Grosso, houve uma grande conversão das florestas naturais em áreas de pastagens, o que gera um impacto nas áreas de drenagens.

Chaves; Santos (2009) afirmam que a ocupação acelerada das bacias hidrográficas pode acarretar problemas tanto com a quantidade, como a qualidade da água. Vanzela et al. (2010) complementam que a retirada da vegetação que protege os mananciais possui como principal consequência o assoreamento, que modifica a qualidade da água, fauna e flora, e provoca redução da disponibilidade hídrica. Portanto, é imprescindível que se tenha um planejamento adequado da ocupação de uma bacia hidrográfica, de modo que a qualidade dos recursos hídricos e do solo não venham a ser prejudicados.

Dentre os atributos mensuráveis a nível de bacias hidrográficas estão: área da bacia, densidade de drenagem, coeficiente de compacidade, índice de circularidade e fator de forma (PISSARRA et al. 2004). Além disso, o conhecimento 
do uso e da cobertura do solo é indispensável para um melhor dimensionamento e planejamento das ações de preservação, conservação e recuperação de uma paisagem. Isso, consequentemente, promove uma melhor visualização da ocupação das bacias hidrográficas.

Essas variáveis, juntamente com o conhecimento do tipo de solo e potencial erosivo das chuvas, podem fornecer um modelo de erodibilidade em nível de bacia hidrográfica, que segundo Cuiabano et al. (2018), uma das formas de se verificar a fragilidade ambiental de uma região é com a análise da vulnerabilidade a erosão.

Dentre as ferramentas para esse tipo de estudo destacase o sensoriamento remoto e o geoprocessamento, que são de fundamental importância para o planejamento dessas áreas, pois contribuem com análises temporais e espaciais que refletem na dinâmica de áreas como as bacias hidrográficas (VANZELA et al., 2010; OLIVEIRA et al., 2013; CUIABANO et al., 2017).

A bacia hidrográfica do Rio Santa Helena está inserida numa região de cobertura florestal do tipo floresta ombrófila aberta que possui alta tensão ecológica devido ao desmatamento (MALHEIROS et al., 2009). Logo, é de suma importância verificar seus atributos físicos e conservacionistas para encontrar a melhor forma para implantação de um sistema de manejo integrado da bacia, tanto em nível de microbacia, como de propriedade rural. Portanto, o objetivo deste trabalho é verificar as características físicas da bacia hidrográfica do Rio Santa Helena e criar um modelo empírico de vulnerabilidade a erosão para auxiliar no manejo integrado da bacia.

\section{MATERIAL E MÉTODOS}

2.1. Caracterização da área de estudo

O estudo foi desenvolvido na Bacia hidrográfica do Rio Santa Helena entre os municípios de Alta Floresta e Paranaíta- MT, conforme Figura 1. A região apresenta clima tropical quente e úmido, com temperaturas médias entre 23 e $26^{\circ} \mathrm{C}$ durante o ano, com máximas diárias de 34 a $37^{\circ} \mathrm{C}$. A precipitação pluviométrica é de 2.000 a $2.300 \mathrm{~mm}$ (SEPLAN, 2001). Está enquadrada na classificação climática tipo Aw, segundo Koppen (SOUZA et al., 2013).

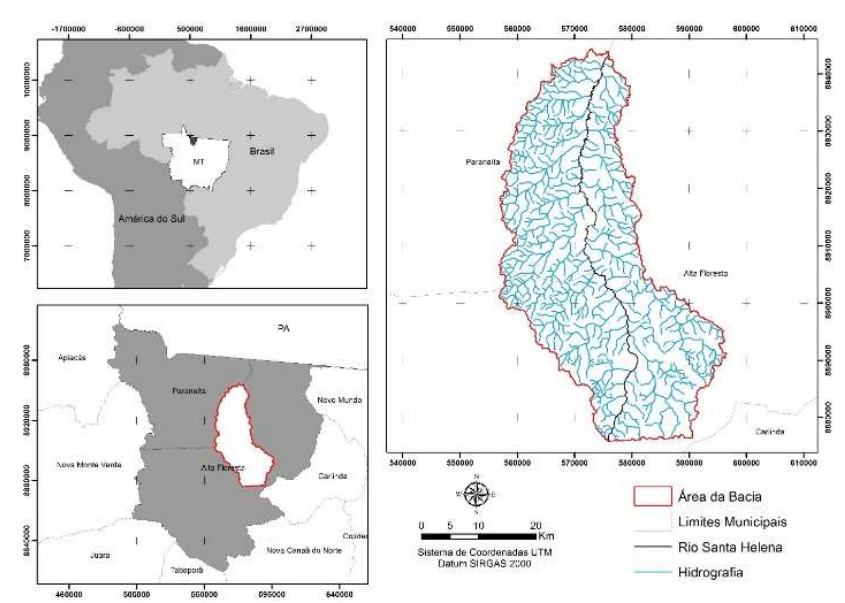

Figura 1. Localização da Bacia Hidrográfica do Rio Santa Helena. Alta Floresta e Paranaíta - MT.

Figure 1. Location of the Santa Helena River Basin. Alta Floresta and Paranaíta - MT.
A classe de solo que predomina na região é Argilossolo Vermelho-Amarelo Distrófico, ocorrendo, como subdominante na maioria das manchas, LATOSSOLO Vermelho-Amarelo e Latossolo Amarelo (IBGE, 2001). A região está situada em uma área de tensão ecológica, possuindo vegetação predominante do tipo ombrófila aberta, com manchas de cerrado em contato com floresta amazônica, e situado na região da depressão interplanáutica de Alta Floresta (SEPLAN, 2001).

\subsection{Processamento dos dados}

Para a realização do trabalho foram obtidas imagens gratuitas adquiridas junto ao United States Geological Survey dos sensores MSI (multi-spectral instrument) a bordo do satélite Sentinel 2 com resolução espacial de $10 \mathrm{~m}$, e SRTM (Shuttle Radar Topography Mission) com resolução espacial de $30 \mathrm{~m}$. Foram utilizadas as bandas 2, 3 e 4 do sensor MSI onde as cenas correspondem às órbitas-ponto 21LWJ e 21LWK referentes ao período de 03 de agosto de 2016. Quanto as imagens SRTM, foram usadas às órbitas- ponto 1S11W057V3 e 1S10W057V3. Para a delimitação da shapefile da Bacia Hidrográfica foram utilizadas imagens SRTM que fornecem dados para geração de um Modelo Digital de Elevação (MDE), todas as análises foram realizadas no software ArcGis 10.1.

Para a avaliação do uso da terra na Bacia do Rio Santa Helena foi utilizado o processo de classificação supervisionada utilizando o algoritmo de máxima verossimilhança, sendo as classes: Floresta Nativa, Agricultura, Pastagem Prodtiva, Pastagem Degradada, Solo Exposto e Espelho D’água.

Classificação é o processo de extração de informação em imagens para reconhecer padrões e objetos homogêneos com o objetivo de mapear as áreas da superfície terrestre. a metodologia empregada no estudo segiu o modelo ralizado por Oliveira et al. (2013).

As características fisiográficas da bacia do Rio Santa Helena foram obtidas segundo as medições de área e perímetro total, calculados através da ferramenta calculate geometry. O coeficiente de compacidade $(\mathrm{Kc})$ foi obtido pela equação 1 (VILLELA; MATTOS, 1975).

$$
\mathrm{Kc}=0,28 \mathrm{P} / \sqrt{\mathrm{A}}
$$

em que: $\mathrm{Kc}=$ coeficiente de compacidade; $\mathrm{P}=$ perímetro da bacia $(\mathrm{km}) ; \mathrm{A}=$ área de drenagem da bacia $\left(\mathrm{km}^{2}\right)$.

O fator de forma $(\mathrm{F})$ foi obtido através da equação 2 (VILLELA; MATTOS, 1975). O Índice de circularidade (IC) foi calculado pela equação 3 .

$$
\mathrm{F}=\mathrm{A} / \mathrm{L}^{2}
$$

em que: $\mathrm{F}=$ fator de forma; $\mathrm{A}$ = área de drenagem da bacia $\left(\mathrm{km}^{2}\right)$; $\mathrm{L}=$ comprimento axial da bacia $(\mathrm{km})$.

$$
\mathrm{IC}=12,57 \mathrm{~A} / \mathrm{P}^{2}
$$

em que: IC = índice de circularidade; $\mathrm{A}=$ área de drenagem da bacia $\left(\mathrm{km}^{2}\right) ; \mathrm{P}=$ perímetro da bacia $(\mathrm{km})$. 
O padrão de drenagem foi identificado por comparação do padrão apresentado pela rede hidrográfica da bacia investigada com os tipos na referência bibliográfica de Pissarra et al. (2004).

O Comprimento do curso d'água principal (Lp) foi estimado por vetorização da distância medida, ao longo do curso d'água principal, entre os pontos extremos (jusante/montante) da bacia, empregando-se o método definido por Shreve (1974). O comprimento total (Lt) dos cursos d'água foram obtidos a partir da soma do comprimento de todos os arcos hidrográficos constantes da bacia de contribuição por meio da vetorização da hidrografia.

O ordenamento dos canais foi feito por meio de vetorização dos mesmos e classificados de acordo com a metodologia de Strahler (1957), em que todos os canais sem tributários são de primeira ordem, os canais de segunda ordem são formados a partir da confluência de dois canais de primeira ordem, podendo ter afluentes de primeira ordem, e assim, respectivamente, para as demais ordens.

A Densidade de drenagem (Dd) foi obtida pela equação 4, proposta por Shreve (1974).

$$
\mathrm{Dd}=\mathrm{Lt} / \mathrm{A} \quad \text { (Eq. 4) }
$$

em que: $\mathrm{Dd}=$ densidade de drenagem $\left(\mathrm{km} \cdot \mathrm{km}^{2}\right) ; \mathrm{A}=$ área de drenagem da bacia $\left(\mathrm{km}^{2}\right) ; \mathrm{Lt}=$ comprimento total dos cursos d'água $(\mathrm{Km})$.

Para a elaboração do mapa de declividade foi utilizado a ferramenta Slope e em seguida foram atribuídos pesos para cada variável de estudo, conforme a Tabela 1, através da ferramenta Reclassify.

A estimativa da erosividade mensal da chuva foi calculada indiretamente, por índice de erosão (EI $\neg 30)$. Segundo Almeida et al. (2009), com a utilização de padrões predefinidos é possível a elaboração de índices de erosão EI30, aplicando modelos matemáticos. De acordo com Jansson (1982), o cálculo da erosividade da chuva é essencial para qualquer previsão da erosão. Nesse sentido, foi utilizada a equação 5, proposta por Morais et al. (1991), que desenvolveram um modelo de erosividade da chuva para o Mato Grosso, com coeficiente $\mathrm{R}^{2}$ de 0,84 .

$$
\mathrm{EI} 30=36.849\left(\mathrm{p}^{2} / \mathrm{P}\right) 1,0852
$$

em que: $\mathrm{EI}=$ Média mensal do índice de erosão em MJmm ano-1 $\mathrm{ha}^{-1} \mathrm{~h}^{-1} ; \mathrm{p}=$ Precipitação média mensal, em milímetros; $\mathrm{P}=$ Precipitação média anual, em milímetros.

Foram utilizados dados referentes a precipitação, sendo de dezembro de 2013 a agosto 2016, obtidos junto a estação meteorológica da Universidade do Estado de Mato Grosso, localizada entre as coordenadas $09^{\circ} 51^{\prime} 43,93^{\prime \prime}$ de latitude sul e $56^{\circ} 04^{\prime} 05,88^{\prime \prime}$ de longitude oeste.A região apresentou EI30 de 967,22 considerado de nível três segundo Soares Filho et al. (1998).

Os dados do tipo de solo foram adquiridos junto ao banco de dados do IBGE em escala 1:1500000, sendo o solo da microbacia classificados como Argissolo Vermelho Amarelo Distrófico. Para a elaboração do mapa de susceptibilidade a erosão foram utilizados os procedimentos de combinação linear e não linear em um primeiro estágio, para serem então seguidos em uma segunda fase, por regras de combinação.

Foram utilizados dados de precipitação, classe de solo, declividade e cobertura do solo, sendo os valores das classes ponderados entre 0 e 1 , com cada classe tendo peso de 0,25 e os valores individuais de cada classe foram ponderados de 1 a 5 de acordo com risco de erosão particular de cada situação (Tabela 1).

Tabela 1. Aspectos utilizados para confecção do modelo de predição a erosão.

Table 1. Aspects used for confection of erosion prediction model.

\begin{tabular}{clc}
\hline Atributos & $\begin{array}{l}\text { Nível de } \\
\text { erosão }\end{array}$ & Fonte \\
\hline
\end{tabular}

\begin{tabular}{lcl}
\hline Classe declividade & 1 & \\
$0 \%-6 \%$ & 2 & Adaptado de Soares \\
$6 \%-12 \%$ & 3 & Filho et al., 1998 \\
$12 \%-20 \%$ & 4 & \\
$20 \%-30 \%$ & 5 & \\
$>30 \%$ & 1 & Adaptado de Soares \\
Classe Erodibilidade do solo & & \\
Gleissolo & 2 & Filho et al., 1998; \\
Latossolo & 3 & Salomão 1999; Ross \\
Argissolo & 4 & 2005. \\
Cambissolo & 5 & \\
Neossolos Litólicos & & \\
Classe uso do solo & 1 & Valores baseados em \\
Vegetação/Agua & 2 & Soares Filho et al., \\
Floresta Plantada & 3 & 1998; Farinaso et al., \\
Pastagem/Agricultura & 4 & 2006. \\
Pastagem degradada & 5 & \\
Solo exposto & & \\
\hline
\end{tabular}

Para combinar as variáveis e criar o mapa de susceptibilidade erosiva, foi utilizado a ferramenta Raster Calculator e inserida a equação: ([Declividade] $* 0,25)+([$ Tipo de solo $] * 0,25)+([\mathrm{EI} 30) * 0,25)+([$ Uso do Solo $] * 0,25)$. Os dados calculados, poderiam apresentar valores de 1 a 5 , e para diferenciação das classes de erosão, esses valores foram separados em quatro classes de risco conforme metodologia adaptada de Soares Filho et al., (1998) sendo: de 1 a 2, de 2 a 3 , de 3 a 4 e de 4 a 5 , respectivamente baixo potencial a erosão, médio potencial a erosão, alto potencial a erosão e muito alto potencial a erosão.

\section{RESULTADOS}

As características fisiográficas da Bacia do Rio Santa Helena são verificados na Tabela 2. A bacia tem uma área de drenagem de 1461,68 km², um perímetro de $329,16 \mathrm{~km}$ e o comprimento axial de $68,81 \mathrm{~km}$.

Os canais de primeira ordem apresentaram um comprimento total de $783,28 \mathrm{~km}$, os canais de segunda ordem apresentaram $304,56 \mathrm{~km}$, enquanto os canais de terceira, quarta e quinta ordem apresentaram, respectivamente, o comprimento de $159,82 \mathrm{~km} ; 77,56 \mathrm{~km}$ e $70,73 \mathrm{~km}$. O comprimento do canal principal totalizou 92,75 $\mathrm{km}$ desde sua nascente à foz (Figura 2).

Quanto ao uso e ocupação do solo foram selecionadas seis classes de cobertura na bacia hidrográfica do Rio Santa Helena, sendo elas: Floresta Nativa, Agricultura, Pastagem Produtiva, Pastagem Degradada, Solo Exposto e Espelho D’água (Figura 3). A área classificada como Floresta Nativa apresentou um total de 61603,3 ha, representando 42,1\% da área total. Essa área florestal é derivada principalmente de 


\section{Atributos físicos e conservacionistas da bacia hidrográfica do Rio Santa Helena}

grandes fragmentos e das Áreas de Preservação Permanente (APP's) em torno dos cursos d'água. As áreas de pastagens somam um total de 61271,6 ha representando $42 \%$ da bacia, sendo 5794,4 ha de áreas de Pastagens Produtivas, representando 4\%, e 55477,2 ha de áreas de Pastagens Degradadas, equivalentes à $38 \%$ da bacia.

Tabela 2. Características fisiográficas da Bacia do Rio Santa Helena. Table 2. Physiographic characteristics of the Santa Helena River Basin.

\begin{tabular}{ll}
\hline Características Fisiográficas & Resultados \\
\hline Área de Drenagem (A) & $1461,68 \mathrm{Km}^{2}$ \\
Perímetro (P) & $329,16 \mathrm{Km}$ \\
Fator de Forma (F) & 0,31 \\
Coeficiente de Compacidade (Kc) & 2,41 \\
Índice de Circularidade (IC) & 0,17 \\
Padrão de Drenagem & Dendrítico \\
Orientação & Norte \\
Comprimento Total dos Canais (Lt) & $1396,18 \mathrm{Km}$ \\
Comprimento do Canal Principal (Lp) & $92,75 \mathrm{Km}$ \\
Comprimento Axial (L) & $68,81 \mathrm{Km}$ \\
Ordem da Bacia & $5^{\mathrm{a}}$ \\
Densidade de Drenagem & $0,96 \mathrm{Km} / \mathrm{Km}^{2}$ \\
\hline
\end{tabular}

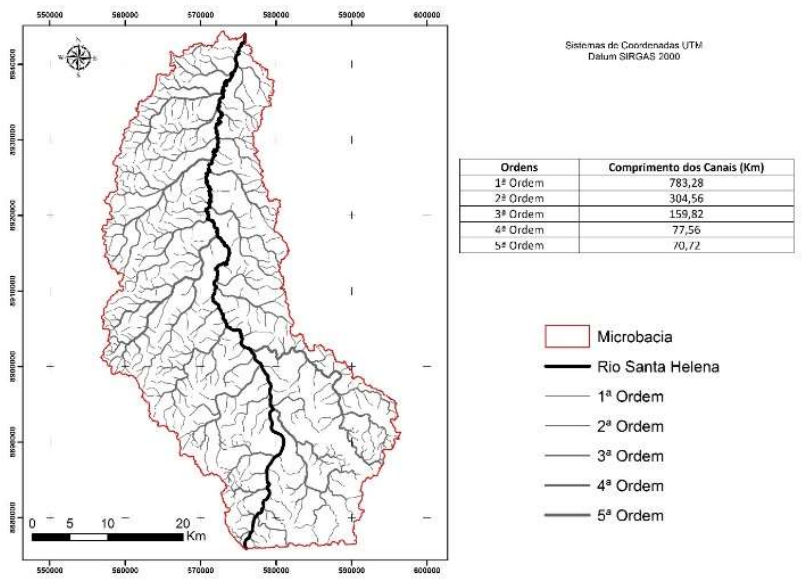

Figura 2. Padrão de drenagens e ordenamento dos cursos de água. Figure 2. Pattern of drainage and arrangement of watercourses.

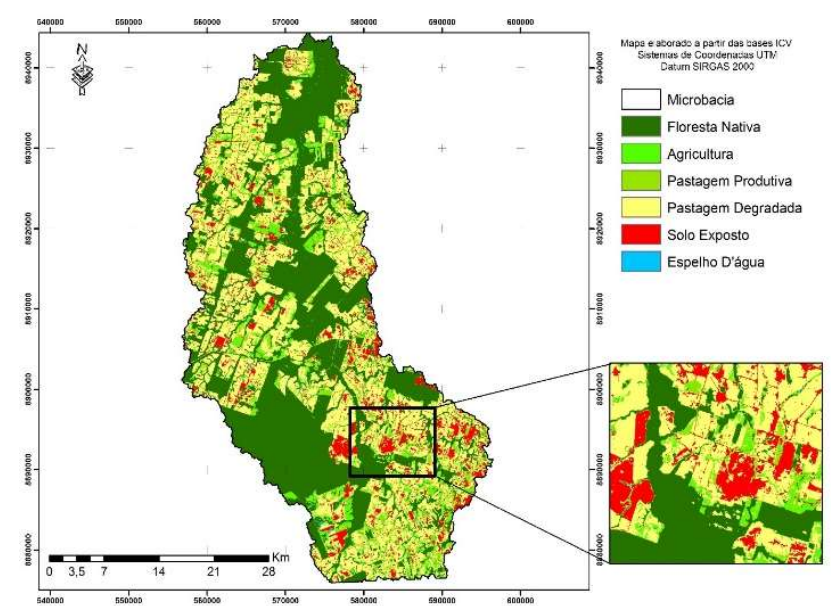

Figura 3. Mapa de uso e ocupação da terra para a Bacia do Rio Santa Helena.

Figure 3. Land use and occupation map for the Santa Helena river basin.

A classe de Solo Exposto apresentou uma área de 10769,9 ha, correspondendo a 7,4\% da área da bacia. Isso deve-se ao fato de muitos agricultores estarem substituindo suas áreas de pastagens por agricultura, realizando o preparo do solo antes de implantar a cultura agrícola. Também devido ao processo de renovação de pastagens, onde é realizado a aragem do solo.

Quanto a declividade da bacia, a mesma possui um relevo plano, onde $76,3 \%$ da área apresentou declividade de $0 \%-6 \%$, apenas 2,4\% da área apresentou declividade de 20\%-30\% e $21,3 \%$ apresentou declividade acima de 30\%. (Figura 4).

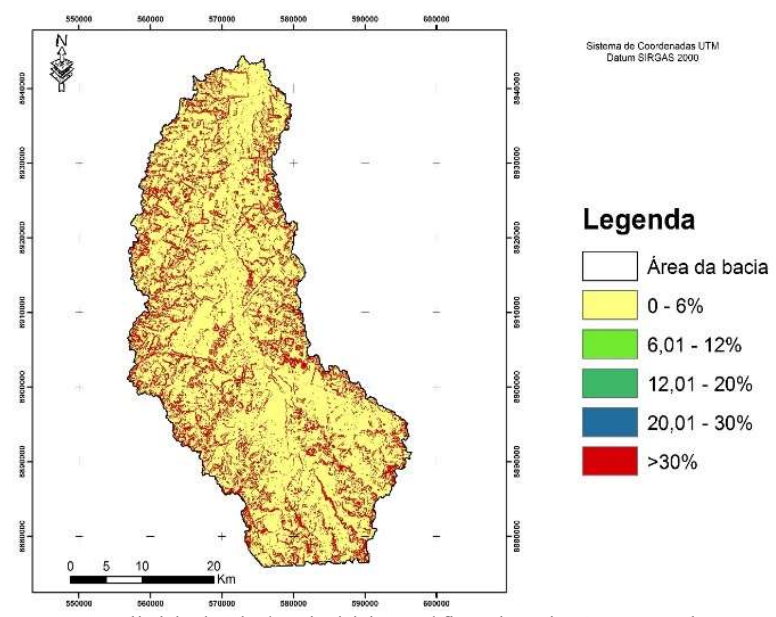

Figura 4. Declividade da bacia hidrográfica do Rio Santa Helena. Figure 4. Santa Helena River watershed declivity.

Foi possível observar a susceptibilidade do solo da bacia hidrográfica do Rio Santa Helena à erosão (Figura 5), onde $31,0 \%$ da área da bacia apresentou baixo potencial à erosão, estando localizadas principalmente nas áreas de floresta nativa. Já nas áreas de pastagens e agricultura apresentaram de médio a alto potencial erosivo, representando respectivamente $55,9 \%$ e $12,8 \%$ da área total da bacia. Já as áreas que apresentam potencial erosivo muito alto representam apenas $0,2 \%$, ocorrendo em locais com solo exposto e declividade elevada.

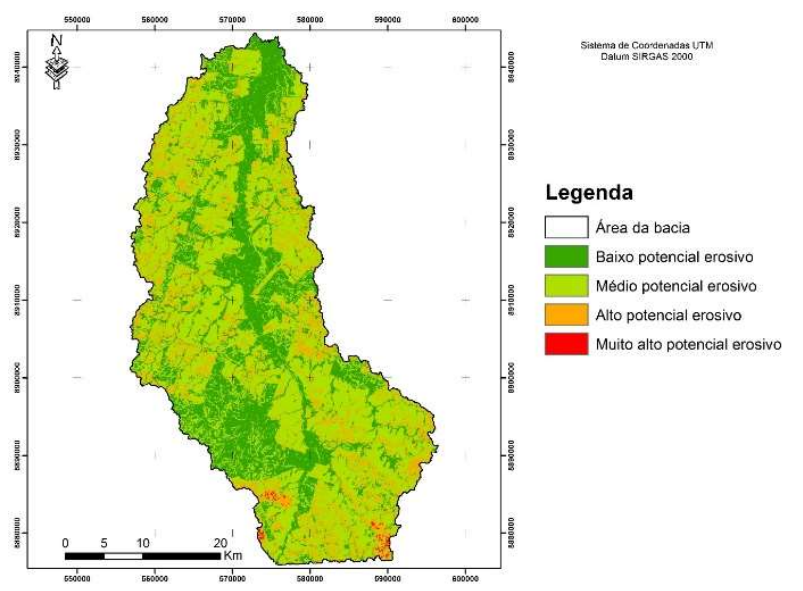

Figura 5. Potencial erosivo da bacia do rio Santa Helena.

Figure 5. Erosive potential of the Santa Helena river basin.

\section{DISCUSSÃO}

De acordo com os resultados do estudo da forma da bacia, o "Kc" obtido foi de 2,41, podendo afirmar que a mesma possui certa irregularidade. De acordo com Carvalho et al. (2009), quanto mais próximo o valor do "Kc" a 1 (um), mais circular é a bacia e maior a tendência de haver picos de 
enchente. Os resultados obtidos para o Fator de Forma e Índice de Circularidade foram respectivamente 0,31 e 0,17, os quais são considerados baixos, indicando assim um maior alongamento da bacia. Devido isso há evidencias que há baixa propensão a valores elevados de vazão e consequentemente baixa tendência de enchentes (CARVALHO et al., 2009). Villela; Mattos (1975) ainda afirmam que numa bacia estreita e longa, com fator de forma baixo, há menor possibilidade de ocorrência de chuvas intensas simultaneamente em toda sua extensão.

O comprimento total dos cursos d'água, distribuídos por todos os seus canais com hierarquia de $5^{\text {a }}$ ordem é de 1396,18 $\mathrm{Km}$. A Densidade de Drenagem é de $0,96 \mathrm{~km} / \mathrm{km}^{2}$, segundo Villela; Mattos (1975), a densidade de drenagem pode variar de $0,5 \mathrm{~km} / \mathrm{km}^{2}$ em bacias com drenagem pobre a 3,5 ou mais nas bacias muito bem drenadas, portanto, a bacia em estudo apresentava baixa capacidade de drenagem.

Santos (2014) encontrou valores para as características fisiográficas da bacia hidrográfica do Córrego do Pinguim em Paranaíta/MT, onde a área de drenagem da bacia em questão foi de $214,0 \mathrm{~km}^{2}$, o comprimento total dos canais foi 809,75 $\mathrm{km}$ e a densidade de drenagem $3,78 \mathrm{~km} / \mathrm{km}^{2}$, caracterizando essa bacia com uma alta capacidade de drenagem, diferente do encontrado na bacia hidrográfica do Rio Santa Helena.

Outra característica importante avaliada é o padrão de drenagens, que para a bacia em questão foi considerado dendrítico. Conforme Pissarra et al. (2004), deriva da interação clima-geologia em regiões de litologia homogênea e lembra a configuração de uma árvore (Figura 2). Essa conformação de drenagem é típica de regiões de climas tropicais úmidos.

Quanto ao uso da terra, outros estudos apresentam valores maiores de áreas abertas como Aragão (2011), encontrou para a bacia do rio Japaratuba, SE, uma remanescente de floresta nativa de apenas $6 \%$, afirmando ainda que essa quantidade tende a diminuir devido influência do avanço da agricultura e pecuária. A grande área de pastagens na área de estudo pode ser explicada pelo método de colonização da região, onde áreas de pastagens serviam como demarcação de território (SPLETOZER et al., 2014).

A preservação da vegetação nativa principalmente em torno dos cursos d'água é essencial para a manutenção dos recursos hídricos de uma bacia hidrográfica, pois servem como um filtro para a malha hídrica, evitando a perda de solo através da erosão superficial, evitando ainda o assoreamento dos rios. Vanzela et al. (2010) afirmam ainda que a cobertura vegetal nativa possui funções ecológicas muito importantes evitando a perda de nutrientes do solo, alteração do clima local e a manutenção da biodiversidade local.

A agricultura representou um total de $8,4 \%$ da área da bacia, isso deve-se ao fato de alguns proprietários estarem substituindo suas áreas de pastagem transformando-as em áreas de plantio agrícola, principalmente com as culturas de milho e soja.

Umetsu et al. (2012) encontraram uma área de pastagem que representa 55,36\% de uma bacia hidrográfica da região de Carlinda MT, confirmando o histórico de colonização do estado.

Para a construção do modelo erosivo a topografia influencia diretamente na intensidade e força do escorrimento superficial da água das chuvas, por isso influencia diretamente na predição erodibilidade da bacia. Segundo Valladares et al. (2012) esse fator está intrinsecamente ligado ao processo erosivo sendo fundamental em modelos de predição erosiva, sobretudo ao comprimento de rampa.

Segundo Cerri et al. (2018), as bacias hidrográficas localizadas em porções escarpadas do terreno sobretudo com alta declividade, apresentam valores maiores para os parâmetros morfométricos, indicando maior potencialidade de ocorrência de escorregamento de terras. Xavier et al. (2010) afirmam que o potencial erosivo está diretamente relacionado com a declividade e o manejo da paisagem, onde áreas de pastagens não conservadas apresentam maior potencial erosivo quando comparadas com áreas de pastagem manejadas corretamente. Quanto a declividade os mesmos autores também verificaram uma relação positiva entre declividade e potencial erosivo na Bacia do Rio Manso, Chapada dos Guimarães.

\section{CONCLUSÕES}

Os resultados obtidos indicam que a caracterização fisiográfica da bacia hidrográfica do Rio Santa Helena apresenta uma forma irregular e alongada, portando confere a mesma um baixo risco de enchentes em condições normais de precipitação. A cobertura da superfície da bacia apresentou grande parte alterada, principalmente com atividades agropecuárias, porém ainda apresente cobertura vegetal nativa preservada, representando $42,1 \%$ da área total. Quanto ao potencial erosivo, a bacia apresenta de baixo a médio risco, principalmente devido à declividade e à cobertura do solo.

\section{REFERÊNCIAS}

ALMEIDA, D. A.; PARENTE JÚNIOR, W. C.; BESSERA NETA, N. C.; COSTA, M. L. Erodibilidade do solo e erosividade da chuva na Serra do Tepequém - Roraima. Revista Acta Geográfica, Boa Vista, v. 3, n .6, p. 39-46, 2009.

ARAGÃO, R.; ALMEIDA, J. A. P.; FIGUEIREDO, E. E.; SRINIVASAN, V. S. Mapeamento do potencial de erosão laminar na bacia do Rio Japaratuba, SE, via SIG. Revista Brasileira de Engenharia Agrícola e Ambiental, Campina Grande, v. 15, n. 7, p. 731-740, 2011. DOI: http://dx.doi.org/10.1590/S141543662011000700012

CARVALHO, W. M.; VIEIRA, E. O.; ROCHA, J. M. J.; PEREIRA, A. K. S.; CARMO, T. V. B. Caracterização fisiográfica da Bacia Hidrográfica do córrego do Malheiro, no município de Sabará-MG. Irriga, Botucatu, v. 14 , n. 3 , p. $398-412$, 2018. DOI: https://dx.doi.org/10.15809/irriga.2009v14n3p398-412

CUIABANO, N. M.; NEVES, S. M. A. S.; NUNES, M. C. M.; SERAFIM, M. E.; NEVES, R. J. Vulnerabilidade ambiental à erosão hídrica na Sub-bacia do Córrego do Guanabara/reserva do Cabaçal-MT Brasil. Geociências, São Paulo, v. 36, n. 1, p. 138-153, 2017. DOI: https://dx.doi.org/10.5016/geociencias.v36i1.12301

CERRI, R. I.; REIS, F. A. G. V.; GRAMANI, M. F.; GABELINI, B. M.; ZAINE, J. E.; SISTO, F. P.; GIORDANO, L. C. Análise da influência de atributos fisiográficos e morfométricos na definição da suscetibilidade de bacias hidrográficas à ocorrência de corridas de massa. Geologia USP, São Paulo, v. 18, n. 1, p. 35-50, $2018 . \quad$ DOI: 
https://dx.doi.org/10.11606/issn.2316-9095.v18133737

CHAVES, H. M. L.; SANTOS, L. B. Ocupação do solo, fragmentação da paisagem e qualidade da água em uma pequena bacia hidrográfica. Revista Brasileira de Engenharia Agrícola e Ambiental, Campina Grande, v. 13, n. sppl., p. 922-930, 2009. DOI: http://dx.doi.org/10.1590/S1415-43662009000700015

FARINASO, M.; CARVALHO JUNIOR, O. A.; GUIMARÃES, R. F. GOMES, R. A. T.; RAMOS, V. R. Avaliação qualitativa do potencial de erosão laminar em grandes áreas por meio goda eups - equação universal de perdas de solos utilizando novas metodologias em SIG para os cálculos dos seus fatores na região do Alto Parnaíba - PI- MA. Revista Brasileira de Geomorfologia, Brasília, v. 7, p. 73-85, n. 2, 2006. DOI: http://dx.doi.org/10.20502/rbg.v7i2.80

FEARNSIDE, P. M. Desmatamento na Amazônia: dinâmica, impactos e controle. Acta Amazonica, Manaus, v. 36, n. 3, p. 395-400, 2006. DOI: http://dx.doi.org/10.1590/S0044-59672006000300018

IBGE_INSTITUTO BRASILEIRO DE GEOGRAFIA E ESTATÍSTICA. EMBRAPA - Mapa de Solos do Brasil. Rio de Janeiro, 2001 - Escala 1:5.000.000. Disponível em: <http://www.ibge.gov.br>. Acesso em 11 abril. 2017.

JANSSON, M. B. Land erosion by water in different climates. Department of Physical Geography, Upsala University. UNGI Rapport no. 57, 1982. 151 p.

MALHEIROS, A. F.; HIGUCHI, N.; SANTOS, J. Análise estrutural da florestal tropical úmida do município de Alta Floresta, Mato Grosso, Brasil. Acta Amazonica, Manaus, v. 39, n. 3, p. 539-548, 2009. DOI: http://dx.doi.org/10.1590/S0044-59672009000300008

MORAIS, L. F.B.; SILVA, V.; NASCHENVENG, T. M. C.; HARDOIN, P. C.; ALMEIDA, J. E. L.; WEBER, O. L. S.; BOEL, E.; DURIGON, V. Índice EI30 e sua relação com o coeficiente de chuva do sudoeste do Mato Grosso. Revista Brasileira Ciência do Solo, Campinas, v. 15, n. 3, p. 339-44, 1991.

OLIVEIRA, F. P.; FERNANDES FILHO, E. I.; SOARES, V. P.; SOUZA, A. L. Mapeamento de fragmentos florestais com monodominância de aroeira a partir da classificação supervisionada de imagens RapidEye. Revista Árvore, v. 37, n. 1, p. 151-161, 2013. DOI: http://dx.doi.org/10.1590/S0100-67622013000100016

PISSARRA, T. C. T.; POLITANO, W.; FERRAUDO, A. S. Avaliação de características morfométricas na relação solo-superfície da Bacia Hidrográfica do Córrego Rico, Jaboticabal (SP). Revista Brasileira de Ciência do Solo, Viçosa, v. 28, n. 2, p. 297-305, 2004. DOI: http://dx.doi.org/10.1590/S0100-06832004000200008

ROSS, J. L. S Geomorfologia: Ambiente e Planejamento. 8ed. São Paulo: Contexto, 2005. 85 p.

SALOMÃO, F. X. T. Controle e prevenção dos Processos Erosivos. In: GUERRA, A. J. T.; SILVA, A. S.; BOTELHO, R. G. M. (Orgs.). Erosão e Conservação dos Solos: Conceitos, Temas e Aplicações. Rio de Janeiro: Bertrand Brasil, 1999. p. 229-265.

SANTOS, S. K. F. Aspectos físicos e conservacionistas da sub-bacia hidrográfica córrego do pinguim em Paranaíta/MT, 2014. 65f. Dissertação (Mestrado) Faculdade de Ciências Biológicas e Agrárias,
Universidade do Estado de Mato Grosso, Alta Floresta, 2014.

SEPLAN/MT. Zoneamento Sócio-econômico Ecológico. PRODEAGRO. Ministério de Integração Nacional, 2001. Disponível em: <http:// www.seplan.mt.gov.br/>. Acesso: 25 de fevereiro de 2018.

SHREVE, R. L. Variations of mainstream length with basin áreaIn river networks; Water Resources Research, Washington, v. 10, n. 6, p. 1167-1177, 1974. DOI: https://dx.doi.org/10.1029/WR010i006p01167

SOARES FILHO, B. S.; CARMO, V. A.; NOGUEIRA, W. J. Metodologia de elaboração da carta do potencial Erosivo da bacia do rio das velhas (MG). Revista Geonomos, Belo Horizonte, v. 6, n. 2, p. 45-54, 1998. DOI: https://dx.doi.org/10.18285/geonomos.v6i2.169

SOUZA, A. P.; MOTA, L. L.; ZAMADEI, T.; MARTIN, C. C.; ALMEIDA, F. T.; PAULINO, J. Classificação climática e balanço hídrico climatológico no estado de Mato Grosso. Nativa, Sinop, v. 1, n. 1, p. 34-43, 2013.

SPLETOZER, A. G.; SANTOS, L. G.; VERÃO, D. S.; RODRIGUES, L.; LOPES, C. R. A. S. Mapeamento das classes de uso e ocupação do solo na fazenda nova vida, Alta Floresta - MT. Enciclopédia Biosfera, Goiânia, v. 10, n. 19, p. 1272 - 1279, 2014.

STRAHLER, A. N. Quantitative analysis of watershed geomorphology. Transactions. American Geophysical Union, Washington, v. 38, p. 913-920. 1957. DOI: https://dx.doi.org/10.1029/TR038i006p00913

TUNDISI, J. G.; TUNDISI, T. M. Impactos potenciais das alterações do Código Florestal nos recursos hídricos. Biota Neotropica, Campinas, v. 10, n. 4, p. 6775, 2010. DOI: http://dx.doi.org/10.1590/S167606032010000400010

UMETSU, R. K.; PEREIRA, N.; CAMPOS, E. M. F. P.; UMETSU, C. A.; MENDONÇA, R. A. M.; BERNASCONI, P.; CAMARGO, M. F. Análise morfométrica e socioambiental de uma bacia hidrográfica amazônica, Carlinda, MT. Revista Árvore, Viçosa, v. 36, n. $1, \quad$ p. 83-92, 2012. DOI: http://dx.doi.org/10.1590/S0100-67622012000100010

VALLADARES, G. S.; GOMES, A. S.; TORRESAN, F. E.; RODRIGUES, C. A. G.; GREGO, C. R. Modelo multicritério aditivo na geração de mapas de suscetibilidade à erosão em área rural. Pesquisa Agropecuária Brasileira, v. 47, n. 9, p. 1376-1383, 2012. http://dx.doi.org/10.1590/S0100-204X2012000900023

VANZELA, L. S.; HERNANDEZ, F. B. T.; FRANCO, R. A. M. Influência do uso e ocupação do solo nos recursos hídricos do Córrego Três Barras, Marinópolis. Revista Brasileira de Engenharia Agrícola e Ambiental, Campina Grande, v. 14, n. 1, p. 55-64, 2010. DOI: http:/ /dx.doi.org/10.1590/S1415-43662010000100008

VILLELA, S. M.; MATTOS, A. Hidrologia aplicada, São Paulo, Indicadores ambientais: conceitos e aplicações, São Paulo: McGraw-Hill, 1975. 245 p.

XAVIER, F. V.; CUNHA, K. L.; SILVEIRA, A.; SALOMÃO, F. X. T. Análise da susceptibilidade à erosão laminar na bacia do Rio Manso, Chapada dos Guimarães, MT, utilizando sistemas de informações geográficas. Revista Brasileira de Geomorfologia, Brasília, v. 11, n.2, p.51-60, $2010 . \quad$ DOI: http://dx.doi.org/10.20502/rbg.v11i2.151 